\section{Social Indicators}

Population (Million):

Population Growth Rate (\%/Year):

GDP (Billion USD):

GDP per Capita (USD):

Gross Savings (Billion USD):

Life Expectancy (Years):

GINI Index:

Human Development Index:
Risk Indicators

18.055
0.806
277.076
15,346
56.834
79.52
50.5
0.843

\section{Major Earthquakes}

$\begin{gathered}\text { Average Annual } \\ \text { Loss (Million USD) } \\ 753.1 \\ 120.5 \\ 30.3\end{gathered}$

\section{Average Annual} Loss Ratio $(\%)$

1.63

1.08

0.58

$\begin{array}{lr}2010 \text { M } 8.8 \text { - Maule-Concepcion } & 402 \text { fatalities } \\ 1960 \text { M 9.5 - Puerto Montt } & \text { 2,000 fatalities } \\ 1939 \text { M 8.3 - Chillan } & 30,000 \text { fatalities }\end{array}$

Seismic Hazard

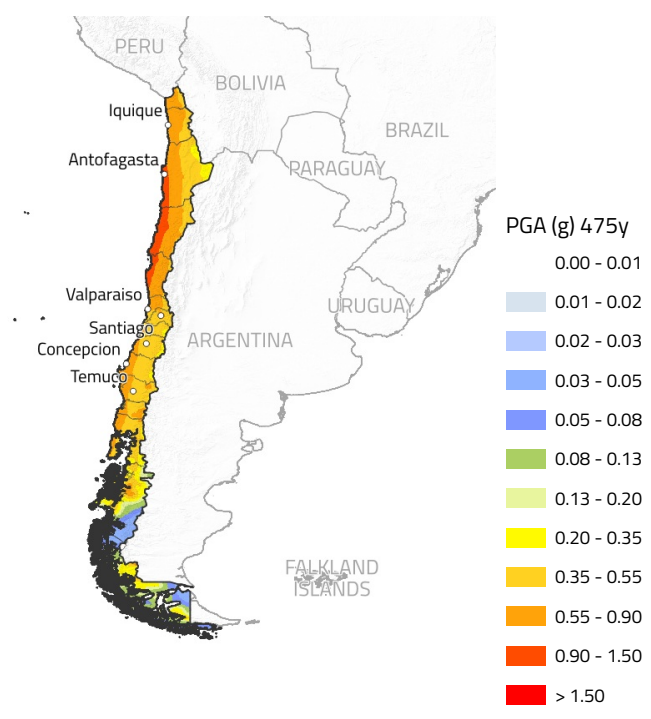

Average Annual Losses

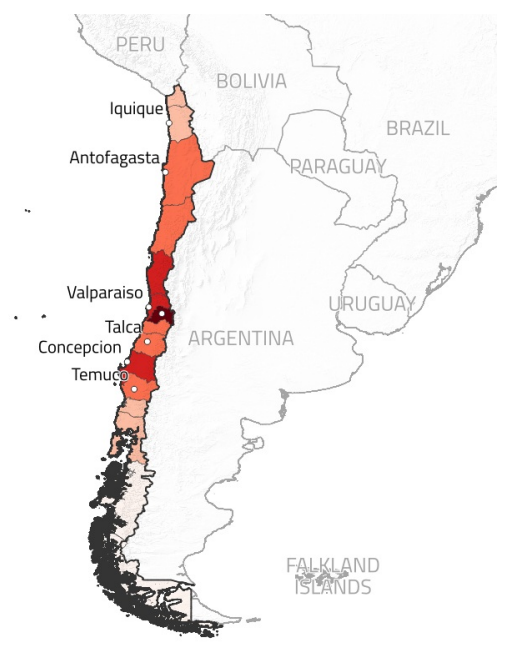

Value (M USD)

$\square 0.6-1.2$

$1.2-21.5$

$21.5-37.4$

प $37.4-82.9$

$82.9-440.9$

Loss Exceedance Curve

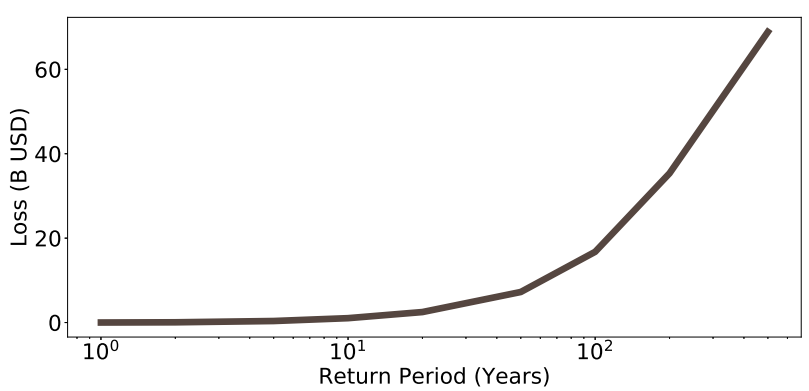

\section{Exposure}

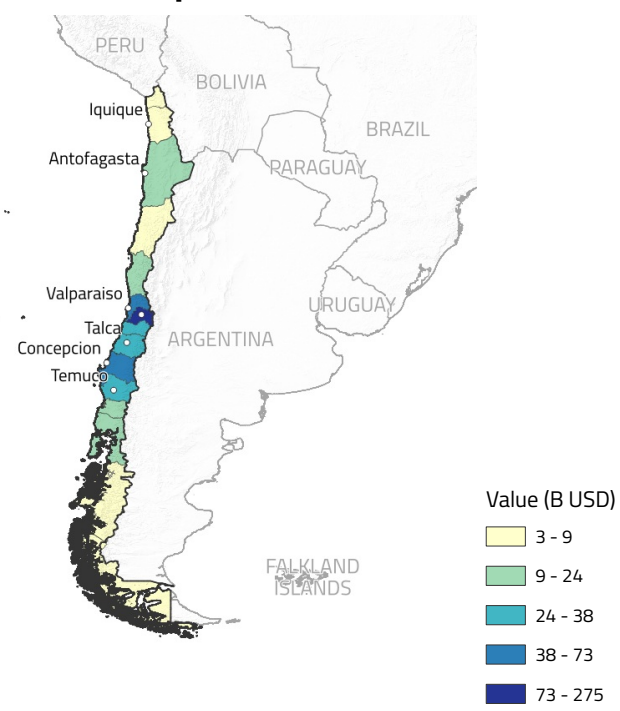

Average Annual Loss Ratios

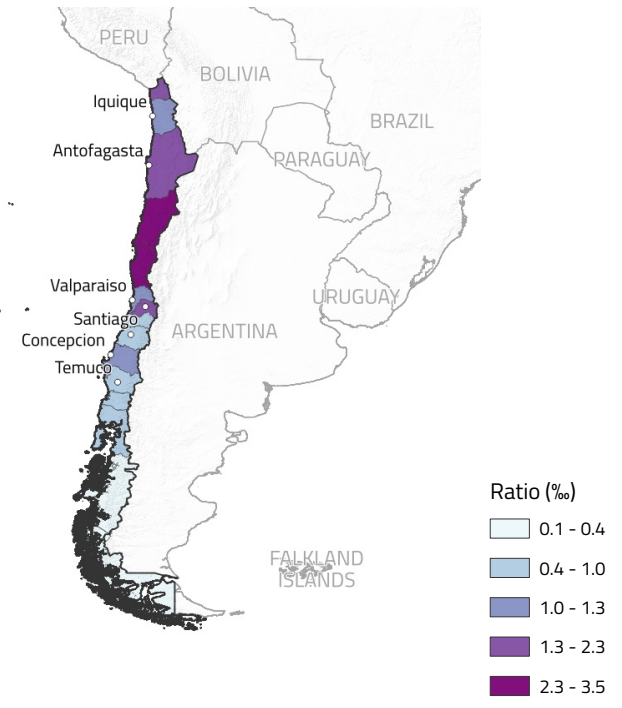


- The primary source for the social Indicators was the World Bank database (https://data.worldbank.org). If no data was available for a country from the World Bank database, the International Monetary Fund (IMF) database (https://data.imf.org), the United Nations (UN) databases (http://www.un.org/en/databases) and The CIA World Factbook 2016-17 (https://www.cia.gov/library/publications/the-world-factbook) published by the US Central Intelligence Agency were used.

- The social indicators listed in the country profiles are for the year 2017 in most cases. For indicators where data for 2017 was not available for a country, data from the most recent year where the indicator is available is presented in the country profile. In future releases of the country profiles, the year associated with each indicator will be included explicitly.

- The seismic hazard map depicts the geographic distribution of the Peak Ground Acceleration (PGA) with a 10\% probability of being exceeded in 50 years, computed for reference rock conditions (shear wave velocity, Vs30, of 760-800 m/s). The seismic hazard maps displayed in the country profiles are based on the Global Earthquake Model (GEM) Global Seismic Hazard Map (version 2018.1), clipped to the country boundary. The Global Seismic Hazard Map was created by collating maps computed using national and regional probabilistic seismic hazard models developed by various institutions and projects, and by GEM Foundation scientists.

- The average annual loss represents the long-term mean loss value per year due to direct damage caused by earthquake ground shaking in the residential, commercial and industrial building stock, considering structural and non-structural components and building contents.

- The average annual loss ratio for the country (or subdivision) represents the average annual loss normalized by the total asset replacement cost within the country (or subdivision).

- The 200-year return period loss represents the long-term mean loss value due to direct damage caused by earthquake ground shaking in the residential, commercial and industrial building stock, considering structural and non-structural components and building contents, that is expected to be equalled or exceeded at least once every 200 years.

- The OpenQuake-engine, an open-source seismic hazard and risk calculation software supported by the GEM Foundation, was used to calculate the hazard and risk metrics presented in the country profiles.

- The maps and risk estimates displayed in this country profile, and the underlying databases are based on best available and publicly accessible datasets and models. The seismic hazard, exposure and vulnerability models employed in these calculations were provided by national institutions, or developed within the scope of regional programs or bilateral collaborations.

- The criterion used for the selection of the major earthquakes for display in the country profiles considered earthquakes causing the largest number of fatalities that occurred in the last 100 years (1918-2018). Fatalities due to tsunamis were excluded. 